\title{
Studying the Interrelationship amongst Possible Factors Affecting Sexual Assault and Sexual Objectification amongst Girl Child, Teenage Girls and Women in India
}

\author{
Neeta Panchmukh \\ MIT School of Education \& \\ Research \\ MIT Art, Design \& \\ Technological University \\ Pune, India
}

\author{
Veena Aggarwal \\ Recventure Education Services \\ Private Limited \\ Delhi, India
}

\author{
Remica Aggarwal \\ MIT School of Education \& \\ Research \\ MIT Art, Design \& \\ Technological University \\ Pune, India
}

\begin{abstract}
Child sexual abuse (CSA) is a serious and widespread problem in India as it is in many parts of the world today. The trauma associated with sexual abuse is so intense that it lead to host of psychological and emotional disorders which are sometimes beyond human control. Also in Indian context, the scenario becomes different other criteria such as poverty, lack of recreational facilities, crowded and unhygienic living conditions, multiple care giving to children etc. also gets appended to worsen the situation.

Objectification in layman sense is reducing a someone to a something - represents a powerful and potentially damaging way in which we can see and treat others. Women are often victims of processes of objectification that occur whenever a woman is reduced to her body or certain body parts. What remains unclear is the extent to which a woman becomes an object when objectified. Women may respond to being sexually objectified in different ways such as confronting the perpetrator, ignoring the action, blaming oneself or considering the action as flattering
\end{abstract}

Present research work focuses on exploring the research area of child sexual assault and sexual objectification amongst women, its need and fallacy as well as various factors involve in child abuse and sexual objectification of women and then establishing the inter-relationships amongst them through ISM methodology .

\section{Keywords}

Interpretive Structural Modeling, Mic-Mac Analysis, Child Sexual abuse (CSA), Sexual Objectification

\section{INTRODUCTION}

Child maltreatment also refer to as child sexual abuse (CSA) particularly in developing country such as India, is quite prevalent and often results in immediate negative effects on children [1-5]. The effect is so intense that entire growth of child gets hinder. the aftermaths include mental disorders, anxiety, depression, anger, cognitive distortions, posttraumatic stress, identity disturbance, interpersonal problems, self-mutilation, unsafe or dysfunctional sexual behavior, aggression, suicidality, and personality disorders are to name a few. Incidence rates of CSA in India are much higher than have been typically acknowledged in the general society and even by many family members. As per the recent reports of CSA an estimated $50 \%$ of the children on the street, at work are exposed to the risk of child abuse, neglect and sexual assault [1-5]. As per the researcher's studies, in India roughly $18 \%-50 \%$ of their country's population may have experienced some type of sexual abuse in their life time.
Iravani's [5] examination of studies of CSA in India,

approximately $30 \%$ of men and $40 \%$ of women remember having been sexually molested during childhood. These incidences could be directly linked with the molestation by family members or with perpetrators outside the immediate or extended family.

In the Indian context, caste plays a particularly significant role both in defining expectations and in shaping interactions at and around school, and members of the SC/ST groups are much less likely to attend or stay in education than other children, especially girls. In a study conducted in the Karnataka state districts of Bijapur and Bagalkot [7-8], it was found that these states have the highest rate of dropouts. Further, many adolescent girls are "missing" from their natal households, likely due to movement to their husband's home following child marriage.

Our interactions among humans are typically determined by our willingness to know other people's thoughts, attitudes, desires and intentions. These typical interaction patterns are normally clearly distinct as separate brain regions with the elaboration of human vs. non-human stimuli [9]. Still, there are instances when the human-object divide tends to fade. This occurs when people objectify other human beings. Objectification occurs whenever a someone becomes a something. In the case of sexual objectification, this someone is typically a woman whose body or body parts are seen as mere instruments, separated from her personality and individuality, regarded as if they were capable of representing her [10-11]. Hence, much like objects that are mostly valued for their appearance or usefulness, when objectified, women are especially appraised for their attractiveness and instrumental value. What remains unclear is whether objectified women become truly similar to objects or whether the object reference is a mere metaphor.

The representation of women in the media is often objectifying and hardly compensated with more empowering imagery in most of the Western world [12-13]. Such direct and indirect objectifying experiences have consequences that negatively impact women's self-views [14-15] . Moreover, perceiving a woman in objectifying terms increases sexual harassment [14-15]. Therefore, getting a better understanding of the processes that underlie sexual objectification is of utmost importance. Present research work explores the various factors contributing to child sexual abuse and mental harassment as well as sexual objectification of women in context of India . The paper is arranged as follows : Section 2 is divided into two sections. Section 2.1 describes various factors contributing towards sexual abuse/ child sexual abuse 
and section 2.2 describes the various factors contributing towards sexual objectification . Thereafter in section 3, ISM methodology is discussed which can be applied to study and establish the relationships. Finally, managerial implications are provided in section 4 .

\section{LITERATURE REVIEW \\ 2.1 Factors contributing to child sexual abuse [16-23]}

This section focused on four prominent forms of child abuse, including physical abuse, sexual abuse, emotional abuse; and child neglect. Most contributing factors towards sexual assault and child abuse are as follows:

2.1.1 Overpopulation (OVP): This is the prime cause of poverty, illiteracy, abandonment of children and often underreporting of child abuse cases.

2.1.2 Wrong and dominating beliefs of parents (WDB): Parents consider their children are their personal property and therefore they are the sole owner as well as circulator of their rights and choices [1-5].

2.1.3 Lower Status and residence in rural area ( LSRRA): Girls who occupy the lower status in the family and society as well as those residing in rural areas are often discriminated against education, nutrition, medical care etc.

2.1.4 Family secrecy (FS): Owing to the cultural elements of blame and shame, often family members go in great length to protect the reputation of the family in the community. . Therefore, any act which could bring shame and blame on the family name is often kept as private.

2.1.5 Lack of counselling (LOC): Often parents and other family members, in order to protect the reputation of family, compel their girls to forfeit the need for counseling and any other medical help even when the girls were suffering from significant mental and emotional symptoms of sexual abuse .

2.1.6 Mental, physical and social problems (MPS): It has been observed by $[3,5]$ in their Kolkatta based study of sexually abused trafficked children, that often these children suffer with mental, physical and social problems, and that depression, loneliness and loss of interest were characteristic of nearly every child. It was observed that about three-fourths $(73.3 \%)$ of the trafficked sexually abused girls were lured with promises of job prospects as well as marriage and a better life.

2.1.7 Place of residence / locality (POR/L) : The results indicated that $93 \%$ of the sexually abused girls came from families that were rural, poor, low in educational background, and of a nuclear family structure [4]

2.1.8 Education System barriers (ESB): These barriers include poor quality education ; harassment by teachers and 'teasing' by boys ; lack of toilet facilities for girls / sanitation problem ; child marriage ; lack of support from family; influence of peers as well as interpersonal factors such as not valuing education [18]. School is not necessary a safe space, and the environment can be 'sexually charged' [19]. Harassment and rape are prevalent internationally as part of girls' experiences of school [20].

2.1.9 Paradoxial behavior of society (PBS) : According to Sahay, the sexually abused girls found it difficult if not impossible to forgive the abuser or forget the trauma of their sexual abuse. In addition, the paradoxical behavior of the girls' family members became a new source of trauma.
2.1.10 Social discrimination and rejection (SDR): Social discrimination and rejection by family members were common experiences of the abused children. HIV/AIDS was found in $14.6 \%$ of the sexually abused children.

2.1.11 Forced act by family members (FAFM): . In a study of sexually abused girls and their family members in Western Madya Pradesh, it was found that, despite the fact that legal action was taken against the perpetrators of sexual abuse whether in or outside the family, the family members of many of the sexually abused girls forced the victims to keep the behavior of the abuser a secret.

2.1.12 Risky sexual behavior and absence of use of contraceptives (RSB): In a study by [21-22], it is found that such children are likely to indulge in risky sexual behavior, be unable to use contraception correctly, and are prone to various STDs/HIV infections.

2.1.13 Increased use of alcohol (IUA) : Lin et al. [23] reported that many young men indulged in unwarranted, unsolicited verbal comments, whistling, jostling, touching, and harassing girls as a form of proving their masculinity. The incidents gets provoked with increased use of alcohol.

\subsection{Factors contributing to sexual objectification amongst women [24-32]}

Presents section reviews the literature associated with various factors leading to sexual objectification amongst women and their response towards them.

2.2.1 Types of sexist actions : Indeed, the willingness to take action varies depending on the type of sexist action. This includes the target's exposure to hostile and benevolent sexism ; target's gender identification ; power of the perpetrator ; expected social costs of confronting the perpetrator ; appearance focus ; morality and competence and time course of processing race and facial expressions [2426] .

2.2.2 The power recall task and social power : This is very common and has been examined by previous researchers [27-31]. Common research topics include power effects on objectification ; social power on sexual objectification using a combination of behavioral and electrophysiological evidence .

2.2.3 Emotions and sexual objectification : feelings of anger and disgust : Sexual objectification in the layman terms may be defined as someone being regarded as an object for sexual pleasure rather than as a human being [33-37]. This may but not obligatorily involves body evaluation which may include the inappropriate sexual remarks or leering or could also include unwanted sexual advances. Such sexist experiences may elicit a variety of emotions. For example, research has suggested that being objectified is likely to promote feelings of anger and disgust. The emotion that is elicited is likely to depend on the individual's interpretation of the situation .Anger is likely when a moral violation is viewed as harming the target's individual rights and disgust is likely when this action is believed to harm the purity of the body or soul

2.2.5 Self-critical emotions : Feeling of shame and lower moral and competence status : Sexual objectification may also elicit self-critical emotions [33-37]. There are various self-critical emotions. Following an instance of sexual objectification, people may feel shame when they think. This action reflects a specific self-defect (e.g., "Being objectified undermines my competence"), inferiority when this reflects a global self-defect (e.g. "Being objectified suggests I am 
powerless and worthless") and rejection when they believe that they are likely to be judged negatively by others (e.g., "Being objectified might result in others not respecting me"). Objectification undermine the target's moral and competence status.

\section{INTERPRETIVE STRUCTURAL MODELLING METHODOLOGY}

Warfield [37] proposed the ISM technique in 1974. The process goes through the various steps viz. identifying the relevant elements and establishing a contextual relationship amongst them; then an Structural self- interaction matrix is developed to establish the lead to relationship amongst the two variables $i \& j$. An initial reachability matrix is then created which eventually leads to the development of final reachability matrix and thereafter reachability set and antecedent set for each criterion. In every iteration a top level element is selected for which the reachability set and intersection sets are the same. The process ended with constructing a diagraph .

\section{DEVELOPMENT OF ISM MODEL}

This section is divided into two parts. In section 4.1 various factors contributing to sexual abuse in teenagers as well as sexual objectification amongst women is described. As a matter of illustration, factors affecting child abuse are further studied for the possible inter-relationships amongst them using ISM methodology in section 4.2 .

\subsection{Factors affecting child abuse and sexual objectification amongst women}

Around 13 collective factors affecting sexual assault amongst teenagers in India have been identified viz. Overpopulation (OVP); Wrong and dominating beliefs of parents (WDB) ; Lower Status and residence in rural area ( LSRRA) ; Family secrecy (FS); Lack of counselling (LOC); Mental, Physical and social problems (MPS); Place of residence / locality
(POR/L) ; Problem in Education system (PES); Paradoxial behavior of society (PBS); Social discrimination and rejection (SDR) ; Forced act by family members (FAFM); Risky sexual behavior and absence of use of contraceptives (RSB); Increased use of alcohol (IUA).

Similarly, around 12 factors that affects or intensifies the feeling of sexual objectification are identified viz. the target's exposure to hostile and benevolent sexism ( EHBS); Target's gender identification (TGI); The power of the perpetrator (PoP) ; Expected social costs of confronting the perpetrator (ESCC); Appearance focus ( AF); Morality and Competence $(\mathrm{M} \& \mathrm{C})$; Time course of processing race and facial expressions (TCP); The power recall task and social power (PRT\&SP) ; Feeling of shame (FoS); Feeling of lower competence and status (FLCS); Feeling of anger and disgust (FoAD) ; Power recall tasks / Social power (SP ). These factors are now been studied for the possible interrelationships through ISM methodology in the next section.

\subsection{Case example Studying inter- relationships amongst factors affecting child sexual abuse}

\subsubsection{Construction of Structural Self -} Interaction Matrix (SSIM)

This matrix gives the pair-wise relationship between two variables i.e. $\mathrm{i}$ and $\mathrm{j}$ based on VAXO. SSIM has been presented below in Fig 1 .

\subsubsection{Construction of Initial Reachability \\ Matrix and final reachability matrix}

The SSIM has been converted in to a binary matrix called the initial reachability matrix shown in fig. 2 by substituting $\mathrm{V}, \mathrm{A}$, $\mathrm{X}, \mathrm{O}$ by 1 or 0 as per the case. After incorporating the transitivity, the final reachability matrix is shown below in the Fig 3 .

Fig 1.1: SSIM matrix for pair wise relationship amongst factors affecting sexual assault amongst teenagers

\begin{tabular}{|c|c|c|c|c|c|c|c|c|c|c|c|c|c|c|}
\hline $\begin{array}{c}\text { S. } \\
\text { No. }\end{array}$ & Barriers & 1 & 2 & 3 & 4 & 5 & 6 & 7 & 8 & 9 & 10 & 11 & 12 & 13 \\
\hline & & OVP & WDB & LSRRA & FS & LOC & MPS & POR/L & PES & PBS & SDR & FAFM & RSB & IUA \\
\hline 1 & OVP & & O & V & O & V & V & V & V & V & V & V & V & O \\
\hline 2 & WDB & & & A & X & A & V & A & A & A & V & A & V & V \\
\hline 3 & LSRRA & & & & V & V & V & V & V & V & V & V & V & V \\
\hline 4 & FS & & & & & A & V & A & V & A & V & V & V & V \\
\hline 5 & LOC & & & & & & V & A & X & A & A & X & V & V \\
\hline 6 & MPS & & & & & & A & A & A & A & A & X & X \\
\hline 7 & POR/L & & & & & & & & X & X & A & A & V & V \\
\hline 8 & PEB & & & & & & & & & A & V & V & V & V \\
\hline 9 & PBS & & & & & & & & & V & V & V & V \\
\hline 10 & SDR & & & & & & & & & & & V & V & V \\
\hline 11 & FAFM & & & & & & & & & & & & V & V \\
\hline 12 & RSB & & & & & & & & & & & & V \\
\hline 13 & IUA & & & & & & & & & & & & \\
\hline
\end{tabular}


Fig 1.2: SSIM matrix for pair wise relationship amongst factors affecting sexual objectification amongst women

\begin{tabular}{|c|c|c|c|c|c|c|c|c|c|c|c|c|c|}
\hline $\begin{array}{c}\text { S. } \\
\text { No. }\end{array}$ & Barriers & 1 & 2 & 3 & 4 & 5 & 6 & 7 & 8 & 9 & 10 & 11 & 12 \\
\hline & & EHBS & TGI & PoP & ESCC & AF & M\&C & TCP & PRT\&SP & FoS & FLCS & FoAD & SP \\
\hline 1 & EHBS & & A & A & O & X & V & A & A & V & V & V & A \\
\hline 2 & TGI & & & O & O & V & V & V & A & V & V & V & A \\
\hline 3 & PoP & & & & V & V & V & V & X & V & V & V & V \\
\hline 4 & ESCC & & & & & O & V & V & X & V & V & V & A \\
\hline 5 & AF & & & & & & V & V & A & V & V & V & A \\
\hline 6 & M\&C & & & & & & & V & A & V & V & V & A \\
\hline 7 & TCP & & & & & & & & A & V & V & V & A \\
\hline 8 & PRT\&S & & & & & & & & & V & V & V & A \\
\hline 9 & FoS & & & & & & & & & & V & V & A \\
\hline 10 & FLCS & & & & & & & & & & & V & A \\
\hline 11 & FoAD & & & & & & & & & & & & A \\
\hline 12 & SP & & & & & & & & & & & \\
\hline
\end{tabular}

Fig 2: Initial reachability matrix for factors affecting child sexual abuse

\begin{tabular}{|c|c|c|c|c|c|c|c|c|c|c|c|c|c|c|}
\hline S. & Barriers & 1 & 2 & 3 & 4 & 5 & 6 & 7 & 8 & 9 & 10 & 11 & 12 & 13 \\
\hline & & OVP & WDB & LSRRA & FS & LOC & MPS & POR/L & PEB & PBS & SDR & FAFM & RSB & IUA \\
\hline 1 & OVP & 1 & 0 & 1 & 0 & 1 & 1 & 1 & 1 & 1 & 1 & 1 & 1 & 0 \\
\hline 2 & WDB & 0 & 1 & 0 & 1 & 0 & 1 & 0 & 0 & 0 & 1 & 0 & 1 & 1 \\
\hline 3 & LSRRA & 0 & 1 & 1 & 1 & 1 & 1 & 1 & 1 & 1 & 1 & 1 & 1 & 1 \\
\hline 4 & FS & 0 & 1 & 0 & 1 & 0 & 1 & 0 & 1 & 0 & 1 & 1 & 1 & 1 \\
\hline 5 & LOC & 0 & 1 & 0 & 1 & 1 & 1 & 0 & 1 & 0 & 0 & 1 & 1 & 1 \\
\hline 6 & MPS & 0 & 0 & 0 & 0 & 0 & 1 & 0 & 0 & 0 & 0 & 0 & 1 & 1 \\
\hline 7 & POR/L & 0 & 1 & 0 & 1 & 1 & 1 & 1 & 1 & 1 & 0 & 0 & 1 & 1 \\
\hline 8 & PEB & 0 & 1 & 0 & 0 & 1 & 1 & 1 & 1 & 0 & 1 & 1 & 1 & 1 \\
\hline 9 & PBS & 0 & 1 & 0 & 1 & 1 & 1 & 1 & 1 & 1 & 1 & 1 & 1 & 1 \\
\hline 10 & SDR & 0 & 0 & 0 & 0 & 1 & 1 & 1 & 0 & 0 & 1 & 1 & 1 & 1 \\
\hline 11 & FAFM & 0 & 1 & 0 & 0 & 1 & 1 & 1 & 0 & 0 & 0 & 1 & 1 & 1 \\
\hline 12 & RSB & 0 & 0 & 0 & 0 & 0 & 1 & 0 & 0 & 0 & 0 & 0 & 1 & 1 \\
\hline 13 & IUA & 0 & 0 & 0 & 0 & 0 & 1 & 0 & 0 & 0 & 0 & 0 & 0 & 1 \\
\hline
\end{tabular}

Fig 3 : Final reachability matrix for factors affecting child sexual abuse

\begin{tabular}{|c|c|c|c|c|c|c|c|c|c|c|c|c|c|c|c|}
\hline $\mathrm{S}$. & Barriers & 1 & 2 & 3 & 4 & 5 & 6 & 7 & 8 & 9 & 10 & 11 & 12 & 13 & D.P \\
\hline & & OVP & WDB & LSRRA & FS & LOC & MPS & POR/L & PEB & PBS & SDR & FAFM & RSB & IUA & \\
\hline 1 & OVP & 1 & 1 & 1 & 1 & 1 & 1 & 1 & 1 & 1 & 1 & 1 & 1 & 1 & 13 \\
\hline 2 & WDB & 0 & 1 & 0 & 1 & 1 & 1 & 1 & 1 & 0 & 1 & 1 & 1 & 1 & 10 \\
\hline 3 & LSRRA & 0 & 1 & 1 & 1 & 1 & 1 & 1 & 1 & 1 & 1 & 1 & 1 & 1 & 12 \\
\hline
\end{tabular}




\begin{tabular}{|c|c|c|c|c|c|c|c|c|c|c|c|c|c|c|c|}
\hline 4 & FS & 0 & 1 & 0 & 1 & 1 & 1 & 1 & 1 & 0 & 1 & 1 & 1 & 1 & 10 \\
\hline 5 & LOC & 0 & 1 & 0 & 1 & 1 & 1 & 1 & 1 & 0 & 1 & 1 & 1 & 1 & 10 \\
\hline 6 & MPS & 0 & 0 & 0 & 0 & 0 & 1 & 0 & 0 & 0 & 0 & 0 & 1 & 1 & 4 \\
\hline 7 & POR/L & 0 & 1 & 1 & 1 & 1 & 1 & 1 & 1 & 1 & 1 & 1 & 1 & 1 & 12 \\
\hline 8 & PEB & 0 & 1 & 0 & 1 & 1 & 1 & 1 & 1 & 0 & 1 & 1 & 1 & 1 & 10 \\
\hline 9 & PBS & 0 & 1 & 0 & 1 & 1 & 1 & 1 & 1 & 1 & 1 & 1 & 1 & 1 & 11 \\
\hline 10 & SDR & 0 & 1 & 0 & 1 & 1 & 1 & 1 & 1 & 0 & 1 & 1 & 1 & 1 & 10 \\
\hline 11 & FAFM & 0 & 1 & 0 & 1 & 1 & 1 & 1 & 1 & 0 & 0 & 1 & 1 & 1 & 9 \\
\hline 12 & RSB & 0 & 0 & 0 & 0 & 0 & 1 & 0 & 0 & 0 & 0 & 0 & 1 & 1 & 3 \\
\hline 13 & IUA & 0 & 0 & 0 & 0 & 0 & 1 & 0 & 0 & 0 & 0 & 0 & 1 & 1 & 3 \\
\hline & De.P & 1 & 10 & 3 & 10 & 10 & 13 & 10 & 10 & 4 & 9 & 10 & 13 & 13 & \\
\hline
\end{tabular}

\subsection{Level Partition}

From the final reachability matrix, reachability and final antecedent set for each factor are found. The element for which the reachability and intersection sets are same are the top-level element in the ISM hierarchy. After the identification of top level element, it is separated out from the other elements and the process continues for next level of elements. Iterations have been shown from table $1-$ table 11 below .

Table 1: Iteration I

\begin{tabular}{|c|c|c|c|}
\hline $\begin{array}{c}\text { S. } \\
\text { No }\end{array}$ & Reachability set & Antecedent set & $\begin{array}{c}\text { Interse } \\
\text { ction } \\
\text { set }\end{array}$ \\
\hline 1. & $6,12,13$ & $\begin{array}{c}1,2,3,4,5,6,7,8,91 \\
0,11,12,13\end{array}$ & $\begin{array}{c}6,12 \\
13\end{array}$ \\
\hline 2. & $\begin{array}{c}2,4,5,6,7,8,11 \\
12,13\end{array}$ & $\begin{array}{c}1,2,3,4,5,7,8,9 \\
10,11\end{array}$ & $\begin{array}{c}2,4,5,7, \\
8,11\end{array}$ \\
\hline 3. & $\begin{array}{c}2,4,5,6,7,8,10 \\
11,12,13\end{array}$ & $\begin{array}{c}1,2,3,4,5,7,8,9 \\
10\end{array}$ & $\begin{array}{c}2,4,5,7, \\
8,10\end{array}$ \\
\hline 4. & $\begin{array}{c}2,4,5,6,7,8,9,10,1 \\
1,12,13\end{array}$ & $1,3,7,9$ & $1,3,7,9$ \\
\hline 5. & $\begin{array}{c}2,3,4,5,6,7,8,9 \\
10,11,12,13\end{array}$ & $1,3,7$ & $1,3,7$ \\
\hline 6. & $\begin{array}{c}1,2,3,4,5,6,7,8,9 \\
10,11,12,13\end{array}$ & 1 & 1 \\
\hline
\end{tabular}

Table 2: Iteration II

\begin{tabular}{|c|c|c|c|c|}
\hline $\begin{array}{c}\text { S.N } \\
\text { o. }\end{array}$ & Reachability set & Antecedent set & $\begin{array}{c}\text { Intersecti } \\
\text { on set }\end{array}$ & $\begin{array}{c}\text { Lev } \\
\text { el }\end{array}$ \\
\hline 2. & $2,4,5,7,8,11$ & $\begin{array}{c}1,2,3,4,5,7,8,9, \\
10,11\end{array}$ & $\begin{array}{c}2,4,5,7,8 \\
, 11\end{array}$ & \\
& & $10,2,3,4,5,7,8,9$, & $2,4,5,7,8$ \\
& & \\
& 11 & 10 & II \\
& $2,4,5,7,8,10$, & 1,10 & \\
& $\begin{array}{c}2,4,5,7,8,9,10,1 \\
1\end{array}$ & $1,3,7,9$ & $1,3,7,9$ & \\
\hline
\end{tabular}

\begin{tabular}{|c|c|c|c|c|}
\hline 5. & $2,3,4,5,7,8,9$, & $1,3,7$ & $1,3,7$ & \\
& 10,11 & & & \\
\cline { 1 - 4 } 6. & $\begin{array}{c}1,2,3,4,5,7,8,9, \\
10,11\end{array}$ & 1 & 1 & \\
\hline
\end{tabular}

Table 3 : Iteration III

\begin{tabular}{|c|c|c|c|c|}
\hline S.No. & $\begin{array}{c}\text { Reachability } \\
\text { set }\end{array}$ & $\begin{array}{c}\text { Antecedent } \\
\text { set }\end{array}$ & $\begin{array}{c}\text { Intersection } \\
\text { set }\end{array}$ & Level \\
\hline 3. & $\mathbf{1 0}$ & $1,3,9,10$ & 10 & \multirow{2}{*}{ III } \\
\cline { 1 - 4 }. & 9,10 & $1,3,7,9$ & $1,3,9$ & \\
\cline { 1 - 4 } 5. & $3,9,10$ & $1,3,7$ & $1,3,7$ & \\
\cline { 1 - 3 } 6 & $1,3,9,10$ & 1 & 1 & \\
\hline
\end{tabular}

Table 4: Iteration IV

\begin{tabular}{|c|c|c|c|c|}
\hline $\begin{array}{c}\text { S. } \\
\text { No. }\end{array}$ & $\begin{array}{c}\text { Reachability } \\
\text { set }\end{array}$ & $\begin{array}{c}\text { Antecedent } \\
\text { set }\end{array}$ & $\begin{array}{c}\text { Intersection } \\
\text { set }\end{array}$ & Level \\
\cline { 1 - 4 } 4. & $\mathbf{9}$ & $1,3,9$ & $1,3,9$ & \multirow{2}{*}{ IV } \\
\cline { 1 - 4 } 5. & 3,9 & 1,3 & 1,3 & \\
\hline 6. & $1,3,9$ & 1 & 1 & \\
\hline
\end{tabular}

Table 5: Iteration $\mathrm{V}$

\begin{tabular}{|l|l|l|l|l|}
\hline $\begin{array}{l}\text { S. } \\
\text { No. }\end{array}$ & $\begin{array}{l}\text { Reachability } \\
\text { set }\end{array}$ & $\begin{array}{l}\text { Antecedent } \\
\text { set }\end{array}$ & $\begin{array}{l}\text { Intersection } \\
\text { set }\end{array}$ & Level \\
\cline { 1 - 3 } 6. & $\mathbf{3}$ & 1,3 & 1,3 & V \\
\cline { 1 - 3 } & 1,3 & 1 & 1 & \\
\hline
\end{tabular}

Table 6: Iteration VI

\begin{tabular}{|c|c|c|c|c|}
\hline $\begin{array}{c}\text { S. } \\
\text { No }\end{array}$ & $\begin{array}{c}\text { Reachability } \\
\text { set }\end{array}$ & $\begin{array}{c}\text { Antecedent } \\
\text { set }\end{array}$ & $\begin{array}{c}\text { Intersection } \\
\text { set }\end{array}$ & Level \\
\hline 8. & 1 & 1 & 1 & VI \\
\hline
\end{tabular}




\subsection{ISM model}

An ISM model is developed ( as shown in fig. 5 below ) after arranging the elements as per their interaction or dependence relationships.

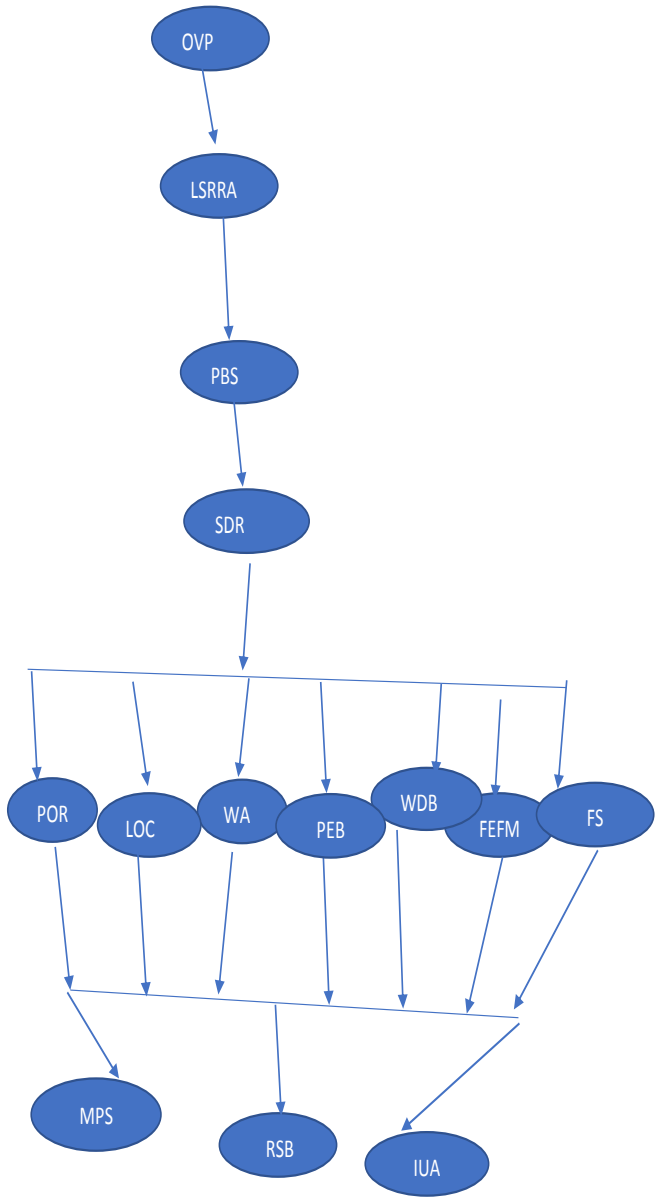

Fig 5 : ISM Model for factors affecting child sexual abuse

\section{LITERARY OBSERVATIONS \& CONCLUSIONS}

1. India is a salient case study, not only for its scale but for the complexities of disadvantage. The socialization and development of adolescent girls is framed by the sociocultural environment [6].

2. Child protection against all kinds of sexual abuse and exploitation needs to be considered at priority basis and current laws need to be enforced when children and adolescents become victims of a perpetrator's acts, including perpetrators being prosecuted to the full extent of the law.

3. The clinical consequences and developmental delays often associated with sexual abuse pose a serious threat to the individual well-being of children and youth, as well as families and communities throughout India.

4. Prevention of child sexual abuse 'requires needed changes at the family, community, state, and national level. Children's rights must continually be at the forefront of local, state, and national government laws and priorities.

5. India's economic boom has fueled the rise of elite private schools for the children of high castes, while the public school system has become a dismal refuge for the children of the lower and middle castes.

6. Further, there is a need to promote a national campaign to educate children and youth, as well as parents and other caregivers, about the nature and prevention of sexual abuse and other forms of abuse and neglect.

7. In addition, law enforcement and the court system must work together in enforcing laws that protect children from all forms of abuse and punish perpetrators to the maximum extent of the law. This is required to send a persistent and powerful message throughout Indian society.

\section{ACKNOWLEDGEMENTS}

Authors are thankful to Prof. S.P Singh, DMS , IIT Delhi for disseminating knowledge on ISM methodology. Our thanks to Dr. Smita Kashiramka, DMS , IIT Delhi for reviewing the manuscript and providing her suggestions to improve the same.

\section{REFERENCES}

[1] Deb, S. 2002. Child Sexual Abuse: An Overview with Special Reference to role of Police, Social Defence, 53(154):44-58

[2] Deb, S., Mukherjee, A. 2011. Background and Adjustment Capacity of Sexually Abused. Girls and their Perceptions on Intervention, Child Abuse Review, 20(3), 213-230.

[3] Chatterjee, P., Chakraborty, T., Srivastava, N., Deb, S. 2006. Short and Long-term Problems Faced by Trafficked Children: A Qualitative Study, Social Science International, 22(1), 167-182.

[4] Joshi , P. 2018. Child sexual abuse in context with India , International Journal of Law, Vol. 4(4), pp.100106.ISSN:2455-2194.

[5] Carson, D.K., Foster, J.M. , Tripathi, N. 2013. Child Sexual Abuse in India: Current Issues and Research, Psychological Studies, 58(3), 318-325. DOI: 10.1007/s12646-013-0198-6 .

[6] Iravani , M.R. 2011. Child Abuse in India, Asian Social Science 7(3).How we measure 'reads'

[7] KHPT, 2012a, KHPT Exploring the Factors That Influence the Retention and Dropout of Adolescent Girls from Educational Institutions in Northern Karnataka

[8] KHPT, 2012b , KHPT Know Me: A Self Exploratory Exercise to Understand Vulnerabilities of Adolescent Girls. A Northern Karnataka Experience

[9] Anderson, C., and Berdahl, J. L. 2002. The experience of power: Examining the effects of power on approach and inhibition tendencies. J. Pers. Soc. Psychol. 83, 13621377. DOI: 10.1037//0022-3514.83.6.1362

[10] Bauser,, D. A. S., and Suchan,, B. 2013. Behavioral and electrophysiological correlates of intact and scrambled body perception. Clin. Neurophysiol. 124, 686-696. doi: 10.1016/j.clinph.2012.09.030

[11] Bernard, P., Content, J., Deltenre, P., and Colin, C. 2018a. When the body becomes no more than the sum of its parts: the neural correlates of scrambled versus intact sexualized bodies. Neuroreport 29, 48-53. DOI: 10.1097/WNR.0000000000000926

[12] Bernard, P., Gervais, S. J., and Klein, O. 2018b . Objectifying objectification: when and why people are 
cognitively reduced to their parts akin to objects. Eur. Rev. Soc. Psychol. 29, 82-121. DOI: 10.1080/10463283.2018.1471949

[13] Bernard, P., Gervais, S. J., Allen, J., Campomizzi, S., Klein, O., and Science, P. 2012. Integrating sexual objectification with object versus person recognition: the sexualized-body-inversion hypothesis. Psychol. Sci. 23, 469-471. DOI: 10.1177/0956797612474669

[14] Loughnan, S., Baldissarri, C., Spaccatini, F., and Elder, L. 2017. Internalizing objectification: objectified individuals see themselves as less warm, competent, moral, and human. Br. J. Soc. Psychol. 56, 217-232. DOI: $10.1111 /$ bjso. 12188

[15] Loughnan, S., Haslam, N., Murnane, T., Vaes, J., Reynolds, C., and Suitner, C. 2010. Objectification leads to depersonalization: the denial of mind and moral concern to objectified others. Eur. J. Soc. Psychol. 40, 709-717. DOI: 10.1002/ejsp.755

[16] Shashikumar, R., Das, R.C., Prabhu, H., Srivastava, K., Bhat, P. S., Prakash, J., Seema, P. 2012. A crosssectional study of factors associated with adolescent sexual activity, Indian J Psychiatry, 54, 138-43.

[17] Siziya, S., Muula, A.S., Kazembe, L.N., Rudatsikira E.2008. Harmful lifestyles' clustering among sexually active in-school adolescents in Zambia. BMC Pediatr 8:6.

[18] Bhagavatheeswaran , L. Nair ,S. Hollie Stone, H. Isac , S., Hiremath , T. , Raghavendra T. , Vadeb K.V.M., Heise, L. , Watts , C., Schweisfurth ,M. Bhattacharjeec, P. and Beattiea, T.S. 2016. The barriers and enablers to education among scheduled caste and scheduled tribe adolescent girls in northern Karnataka, South India: A qualitative study, International Journal of Educational Development, 49, 107-114.

[19] C. Harber Schooling as Violence: How Schools Harm Pupils and Societies, Routledge, London (2004).

[20] G. Chinmaya, J. Dejaeghere, N. Kendall, M.A. KhanGender and education for all: progress and problems in achieving gender equity, Int. J. Educ. Dev., 32 (2012),743-755.

[21] Das, P., Pal, R., Pal, S. 2010. Awareness on psychosomatic health among adolescent girls of three schools in North Kolkata. Indian J Psychiatry, 52, 355359.

[22] Satyanarayana Rao, T.S., and Avasthi , A. 2008. Road map for sexual medicine: Agenda for Indian Psychiatric Society. Indian J Psychiatry, 50, 153-4.

[23] Lin, D., Xiaoming, L., Yang, H., Fang, X., Stanton, B., Chen, X., 2005. Alcohol intoxication and sexual risk behaviors among rural to urban migrants in China. Drug Alcohol Depend, 79,103-12.

[24] Gay, R. K., and Castano, E. 2010. My body or my mind: the impact of state and trait objectification on women's cognitive resources. Eur. J. Soc. Psychol. 40, 695-703. doi: 10.1002/ejsp.731
[25] Gervais, S. J., Holland, A. M., and Dodd, M. D. 2013. My eyes are up here: the nature of the objectifying gaze toward women. Sex Roles 69, 557-570. DOI: 10.1007/s11199-013-0316-x

[26] Gervais, S. J., Vescio, T. K., Förster, J., Maass, A., and Suitner, C. 2012. Seeing women as objects: the sexual body part recognition bias. Eur. J. Soc. Psychol. 42, 743753. DOI: $10.1002 /$ ejsp. 1890

[27] Civile, C., and Obhi, S. S. 2016. Power, objectification, and recognition of sexualized women and men. Psychol. Women Q. 40, 199-212. DOI: $10.1177 / 0361684315604820$

[28] Civile, C., Rajagobal, A. and Obhi, S. S. 2016. Power, ethnic origin, and sexual objectification. Sage Open 6:2158244016646150. $10.1177 / 2158244016646150$

[29] Galinsky, A. D., Gruenfeld, D. H., and Magee, J. C. 2003. From power to action. J. Pers. Soc. Psychol. 85, 453-466. DOI: 10.1037/0022-3514.85.3.453

[30] Guinote, A. 2017. How power affects people: activating, wanting, and goal seeking. Annu. Rev. Psychol. 68, 353381. DOI: 10.1146/annurev-psych-010416-044153

[31] Sturm, R. E. and Antonakis, J. 2015. Interpersonal power: a review, critique, and research agenda. J. Manag. 41, 136-163. DOI: 10.1177/0149206314555769

[32] Xiao, L., Li, B., Zheng, L. and Wang, F. 2019. The Relationship Between Social Power and Sexual Objectification: Behavioral and ERP Data. Front. Psychol. 10:57. DOI: 10.3389/fpsyg.2019.00057.

[33] Heflick, N. A., Goldenberg, J. L., Cooper, D. P., and Puvia, E. 2011. From women to objects: appearance focus, target gender, and perceptions of warmth, morality and competence. J. Exp. Soc. Psychol. 47, 572-581. DOI: $10.1016 /$ j.jesp.2010.12.020.

[34] Bareket , O. and Shnabel, N. 2019. Domination and Objectification: Men's motivation for dominance over women affects their tendency to sexually objectify women , Psychology of Women Quarterly. https://doi.org/10.1177/0361684319871913

[35] Heflick, A. ; Goldenberg, J.L. ; Cooper, D. ; Puvia , E. 2011. From women to objects : Appearance focus , target gender and perceptions of warmth , morality ad competence, journal of experimental social psychology , $47(3), 572-581$.

[36] Fredrickson, B. L., \& Roberts, T. (1997). Objectification theory: Toward understanding women's lived experiences and mental health risks. Psychology of Women Quarterly, 21, 173-206.

[37] Peat, C. M., and Muehlenkamp, J. J. 2011. Selfobjectification, disordered eating, and depression a test of mediational pathways. Psychol. Women Q. 35, 441450. DOI: $10.1177 / 0361684311400389$

[38] Warfield, J. N. 1974. Developing interconnection matrices in structural modeling. IEEE Transactions on System, Man, and Cybernetics, SMC-4 (1), 81-87. 